Theories \& Applications, the International Edition

Printed Version : (ISSN 2090-5262)

Online Version : (ISSN 2090-5270)

November 2014, Volume 4, No. 3 Pages (47 - 57)

\title{
Study of Game-Related Statistics Which Discriminate Between Winning and Losing Basketball Junior Teams U-17 in World Championship.
}

\author{
Dr. Mohamed Abd El-Hamid Belal
}

Associate Professor, Department of Sports Training, Faculty of Sport Education for Men, Alexandria University, Egypt.

\begin{abstract}
The Aims of the research was to identify the game-related statistics which discriminate between winning and losing Basketball teams in FIBA U-17 World Championship for Men, Lithuania, 2012, also Identify the game-related statistics for losing Egyptian Basketball team in the World championship. The researcher used descriptive survey curriculum. The Sample was (40) Games, (8) teams, (4) winning and (4) losing. The researcher used FIBA official Game-related statistics variables to achieve the aims of the research, in addition to the following variable; The Effective Field Goal Percentage, Offensive Rebounds Efficiency Percentage, Defensive Rebounds Efficiency Percentage, Ball possessions and Efficiency. The results allowed understanding the discriminatory power of game-related statistics and allow Basketball coaches to understand that winning team depends on certain variables as it appears in the research. These variables will help coaches to prepare practices according to this specificity and to be ready to control these variables in competition for players under 17, also results allowed coaches to be aware that dominating the following variables will increase the probability to win the games for Junior teams under 17 as: Height of players, Defensive Rebounds Efficiency Percentage, Free-Throws Made, Field-Goal Made, Field-Goal Attempted, The effective field goal percentage and 2 Points Attempted. The most effective statistics variables for losing Egyptian Basketball were height of players, Field-Goal Attempted, 3 Points Made, 3 Points Attempted, Assists, Turnovers and Ball possessions.
\end{abstract}

\section{Introduction:}

$\mathrm{B}$ asketball is one of the distinguished games with several skills and different tactic's situations, which are variables during the competition. That's refer to the nature of the game and the varieties of its skills and game planning, and require from the coach to accurate following players during the game, in order to design tactic and identify the strengths and weaknesses for his team and the opponent's team, that's through the statistics outcomes from the game (Clive G, 2009).

Game- related statistics is using to identify the players and team's strengths and weaknesses, and evaluate the possibility of winning and losing for defensive and offensive strategies, until now there is lack in identifying the most effective factors to achieve the winning and losing teams in basketball games, especially at the end of the game. Although the winning is the main indicator to team's success, but how the team achieves that winning, that's the question that many researchers ask (Csataljay G et al, 2009). Basketball Gamerelated statistics for players and team during the game is one of the main factors that coaches depends on to win the game, it helps the coaches to understand the individuals and team performance, therefore the game tactics. And it has an important role when compare the team with the opponent's performance (Gabor C, 2012; Miguel Á et al, 2008).

Data provided by traditional sport statistics must be analyzed to a greater extent in order to improve the training process and achieve greater control during the competition itself. This is why the discriminatory power of the game statistics on winning and losing teams was beginning to be a focus on research in basketball (Tminic S et al, 2002).

The majority of the researchers analyzed the variables related to the final actions of ball possessions such as shots, efficiency percentage, assists, turnovers, steals, personal fouls received, points scored, etc., or other variables like rebounds or even fast breaks. Most of these studies conclude that two point shots by the team and the efficiency percentage of them are the chief determinants of winning (Miguel Á et al, 2008; Ibáñez et al, 2003). Also, they show the relationship between numbers of rebounds and winning, which is to say a higher numbers of rebound, means better opportunity to win the match (Sampaio J et al, 2004). The reviewed studies identify two-point shots and the number of rebounds as the two most statistically indicative determinants of winning or losing a match in basketball. (Sergio J et al, 2009). Coaches and players should be aware of these results in order to control in a better way the training and the game situation depending on its development, and select basketball players according to specific profiles and have a more precise assessment of the impact of changing to another league or competition upon a teams' game-related statistical profile, e.g., selecting centers with a very high number of defensive rebounds to play in European and World championships or, on the other hand, selecting guards with a very high number of assists and 2 point field-goals percentage to play in the Spanish League. (Miguel A et al, 2008; Sergio J et al, 2009).

However, it seems clear that the discriminant game-related statistics change according to the games specific context, i.e., a regular season game outcome depends upon the 
performance in different variables than a playoff game (Sampaio J and Janeira M, 2003). Therefore, other gamerelated statistics may emerge as discriminant in other specific contexts, such as free-throws (Christoforidis et al, 2000), three-point field goal attempts and assists (Gómez et al, 2006), also attempted to relate the championships final classification with game ball possessions (Gómez $\mathrm{M}$ et al., 2013). Team performance is often fluctuates during basketball matches, therefore more detailed findings can be achieved from analysis of shorter periods of games. Global analyses of whole tournaments and championships also can be misleading when distinguishing performance indicators are identified, because matches with substantial differences between performances of two teams increase the amount of significant indicators. For basketball coaches it is more important to know the critical elements of successful performance that can lead to victory during games. (Gabor C., 2012).

Therefore, the current research identify the effective statistics that discriminate between winning and losing teams in certain age (under 17 years), and during short periods of games ( FIBA U-17 World Championship for Men).

In fact, under 17 years old teams represent the second international competition for basketball teams (FIBA U17 World Championship for Men, Lithuania.2012) and its games analysis may allow understanding how these single characteristic teams achieve game success. Thus, the aim of the present study is to identify the game-related statistics that allow us to discriminate between winning and losing Basketball teams U-17, which qualified the winning teams for the semi- finals games and losing teams for the classification round 9-12, The Egyptian Basketball team participated in this championship and got the last place (rank 12), and didn't win any game, that's what led the researcher to identify the variables of losing the Egyptian team U-17 and compare these variables with the winning teams, and identify the weaknesses for the Egyptian team and suggest Training solutions. That was during the study of the official game-related statistics outcomes from FIBA website (www.fiba.com), in addition to study the following variables; The Effective Field Goal Percentage, Offensive Rebounds Efficiency Percentage, Defensive Rebounds Efficiency Percentage, Ball possessions and Efficiency, which the previous studies showed the importance of these variables to discriminate between winning and losing basketball teams. (Gómez M , 2013; GABOR C, 2012; Miguel Á, 2008; Donald H, 2007) .

Within the limitation of the researcher knowledge and the previous studies, this is the first study to identify the winning and losing variables for Basketball Championship for teams under 17 , and also there is no study mentioned before the winning and losing variables for the Egyptian Basketball Teams through Championship for juniors under 17 , which gives a scientific value for the current study.

\section{Aims of the research:}

1. Identify the game-related statistics which discriminate between winning and losing teams in World Championship U-17 for Men.

2. Identify the game-related statistics for losing The Egyptian team in FIBA U-17 World Championship for Men 2012.

\section{Research Questions:}

1. What are the most effective statistics for discriminating winning and losing teams in World Championship for Men U-17?

2. What are the most effective statistics for losing Egyptian team in FIBA U-17 World Championship for Men 2012?

\section{Previous Studies:}

The Study of (Gabor C et al, 2012) Performance differences between winning and losing basketball teams during close, balanced and unbalanced quarters. Previous studies in basketball performance have tended to assess differences between winners and losers of games. This methodology does not consider the fluctuating nature of scoring within games. Consequently winning and losing performance for each quarter of 26 games of the Hungarian basketball league in 2007/08, The five performance indicators (number of successful free throws, number of defensive rebounds, total amount of rebounds and rebounding percentage in offence and defence) suggest that mainly the success in rebounding might be the critical factor that determines winning and losing in these close situations.

The Study of (Csatalay G et al, 2009). Performance indicators that distinguish winning and losing teams in basketball, The main purpose of this study was to identify those critical performance indicators that most distinguish between winning and losing performances within matches. The analysis of tight matches explored that the winning teams had significantly less 3 point attempts $(p<0.05)$ with higher shooting percentage $(p<0.01)$. The number of successful free throws $(p<0.01)$, the free throw percentage $(p<0.001)$ and the number of defensive rebounds $(p<0.01)$ also contributed to achieve a higher number of scored points and consequently determined success.

The Study of (Sergio J et al, 2009) Effects of consecutive basketball games on the game-related statistics that discriminate winner and losing teams. The aim of the present study was to identify the game-related statistics that discriminated basketball winning and losing teams in each of the three consecutive games played in a condensed tournament format. A discriminant analysis allowed identifying the two-point field goals made, the defensive rebounds and the assists as discriminators between winning and losing teams in all three games. Additionally to these, only the three-point field goals made contributed to discriminate teams in game three, suggesting a moderate 
effect of fatigue. Coaches may benefit from being aware of this variation in game determinant related statistics and, also, from using offensive and defensive strategies in the third game, allowing to explore or hide the three point fieldgoals performance.

The Study of (Haris P et al, 2009) Differences between successful and unsuccessful Basketball teams on the final Olympic Tournament, The aim of the study was to find out global quantitative differences between successful and unsuccessful teams, which had played on the Olympic basketball tournament, The obtained results show that assists, parameters of shooters' field goal efficiency, defensive rebound and number of points made by bench players are variables that make the most significant difference between victorious and defeated teams.

The Study of (Miguel Á et al, 2008) Game Related Statistics that discriminated winning and losing Teams from the Spanish Men's Professional Basketball Teams. The purpose of study was to analyse men's basketball competitions, trying to identify which game-related statistics allow to discriminate winning and losing teams. Discriminant analysis allowed to conclude the following: (i) in balanced games, the variable that best differentiate both groups were the defensive rebounds; (ii) in unbalanced games, the variables that discriminate between both groups were the successful 2 points field-goals, the defensive rebounds and the assists; and (iii) in all games, the statistical analysis identified two variables that discriminate winning and losing teams (defensive rebounds and assists).

The Study of (Sampaio J et al, 2004) Discriminative power of basketball game-related statistics by level of competition and sex, The purpose of this study was to identify the basketball game-related statistics that best discriminate performances by sex of players and level of competition. The game-related statistics gathered included 2- and 3-point field-goals , free-throws, defensive and offensive rebounds, blocks, assists, fouls, steals and turnovers. Men's teams were discriminated from women's teams by their higher percentage of blocks and lower percentage of steals and unsuccessful 2-point field goals. Junior teams were discriminated from senior teams by their lower percentage of assists and higher percentage of turnovers. In the twofactor interaction, the teams were mainly discriminated by the game-related statistics identified for level of competition.

The Study of (Sampaio J \& Janeira, 2003) Statistical analyses of basketball team performance: understanding teams' wins and losses according to a different index of ball possessions. The aim of the present paper is to investigate the discriminatory power of game statistics between winning and losing teams in the Portuguese Professional Basketball League. Obtained results allowed us to understand that in balanced and unbalanced games, losing teams performed poorly in all game statistics. In contrast, results from close games allowed us to identify different team performance profiles according to game type and location. Globally, regular season profile was best discriminated by successful free-throws, whereas play-offs profile was best discriminated by offensive rebounding. On the other hand, home wins were best discriminated by committed fouls whereas successful free-throws discriminated away wins. Coaches and players should be aware of these different profiles in order to increase specificity at the time of game planning and control.

The Study of (Trninic S et al, 2002) Differences between winning and defeated top quality basketball teams in final of European club championship, The aim of this research was to identify parameters among the 12 indicators of situationrelated efficiency that differentiated between the winning and defeated top quality teams which played in final tournaments of the European club championships from 1992 to 2000 . The obtained results suggested that the winning teams showed more of tactical discipline and responsibility in controlling inside positions for defensive rebounds, as well as in controlling play on offense and the ball until the required open shot chance, which considerably reduced game risks and resulted in a lower number of turnovers and in a higher shooting percentage.

From the previous studies, the researcher reached to identify the statistics variables which can be studied to achieve the aims of the research.

\section{Research Methods:}

The researcher used descriptive survey curriculum for its suitable to the nature of the research.

\section{Research Sample:}

- 40 games from FIBA U17 World Championship for Men, Kaunas in Lithuania, 2012.

- Number of sample (8) teams.

- Number of winning teams that qualified for the semi-finals (4) teams (Rank 1-4).

- Number of losing teams (4), (Rank 9-12).

\section{The Time-Frame Area:}

The main study has been achieved during the period from 05/12/2013 till 15/12/2013.

\section{The Scoping Study:}

\section{Aim of the study:}

Identify the participation of the Egyptian Basketball team Under 17 in World Championship.

\section{The Scoping Study Procedures:}

1. The scoping study has been achieved on $01 / 12 / 2013$.

2. Download Game-related statistics for World Championships for Junior Basketball Teams from the FIBA website (www.fiba.com).

3. Determine the participation of the Egyptian Junior Basketball team in World Championships. 


\section{The Result of the Scoping Study:}

Within the scoping study, the researcher found that the Egyptian Junior Basketball Team didn't qualify for the semi- finals in any FIBA Championships, and also didn't participate in (6) championships out of (13) which is cleared in Table (1):

Table (1)

clears the participation of The Egyptian Junior Team in FIBA Championship

\begin{tabular}{|c|c|c|c|}
\hline NO & Event name & Number of Teams & Rank of Egypt Team \\
\hline 1 & 2013 FIBA U19 Championship for Men & 16 & not qualified \\
\hline 2 & 2012 FIBA U17 World Championship for Men & 12 & 12 \\
\hline 3 & 2011 FIBA U19 World Championship for Men & 16 & 11 \\
\hline 4 & 2010 FIBA U17 World Championship for Men & 12 & 11 \\
\hline 5 & 2009 FIBA U19 World Championship for Men & 16 & not qualified \\
\hline 6 & 2007 FIBA U19 World Championship for Men & 16 & not qualified \\
\hline 7 & 2003 World Championship for Junior Men & 13 & not qualified \\
\hline 8 & 1999 World Championship for Junior Men & 16 & 13 \\
\hline 9 & 1995 World Championship for Junior Men & 16 & not qualified \\
\hline 10 & 1991 World Championship for Junior Men & 16 & not qualified \\
\hline 11 & 1987 World Championship for Junior Men & 12 & 12 \\
\hline 12 & 1983 World Championship for Junior Men & 14 & 12 \\
\hline 13 & 1979 World Championship for Junior Men & & 16 \\
\hline
\end{tabular}

\section{The Research Tools:}

- CDs with records of games and statistics of FIBA U17 World Championship 2012.

- Laptop.

- Microsoft Office Excel 2013.

- SPSS Program.

The main experiments research:

- The scoping study was to identify the participating of the Egyptian Junior Basketball Team in FIBA World Championships.
- Obtained game-related statistics from FIBA U17 World Championship for Men, Kaunas in Lithuania, 2012 (29/06 - 08/07/2012), FIBA Website (www.fiba.com).

- The researcher divided 2012 Championship teams into 2 levels, level (1) the winning (4 teams) that qualified for the semi-finals, and level (2) the losing (4 teams) that got the last ranks of the championship (rank 9-12)

Table (2)

clears the teams according to the ranks of winning and losing in the Championship

\begin{tabular}{|c|c|c|c|c|}
\hline Level & Team & Ranking & Win & Lost \\
\hline \multirow{4}{*}{ Winning Teams } & USA & 1 & 8 & 0 \\
\cline { 2 - 5 } & Australia & 2 & 6 & 2 \\
\cline { 2 - 5 } & Croatia & 3 & 7 & 1 \\
\cline { 2 - 5 } & Spain & 4 & 5 & 3 \\
\hline \multirow{3}{*}{ Losing Teams } & Lithuania & 9 & 3 & 5 \\
\cline { 2 - 5 } & France & 10 & 2 & 6 \\
\cline { 2 - 5 } & Korea & 11 & 0 & 7 \\
\cline { 2 - 5 } & Egypt & 12 & & 4 \\
\hline
\end{tabular}

- Determine the official game-related statistics variables from FIBA and use it to achieve the aims of the research according to the previous and related researches and theoretical study: 
1. height of players

2. Field-Goal Made (FGM)

3. Field-Goal Attempted (FGA)

4. Field-Goal Percentage (FG\%)

5. 2 Points Made (2PTSM)

6. 2 Points Attempted (2PTSA)

7. 2 Points Percentage (2PTS\%)

8. 3 Points Made (3PTSM)

9. 3 Points Attempted (3PTSA)

10. 3 Points Percentage (3PTS\%)

11. Free-Throws Made (FTM)

12. Free-Throws Attempted (FTA)

13. Free-Throws Percentage (FT\%)

14. Offensive Rebounds (OR)

15. Defensive Rebounds (DR)

16. Total Rebounds (REB)

17. Assists (AST)

18. Personal Fouls (PF)

19. Turnovers (TO)

20. Steals (ST)

21. Block Shots (BS)

(Gabor C et al, 2012; Sergio J et al, 2009; Miguel Á, 2008; Trninic $S$ et al, 2002)

- Based on the previous researches and theoretical study, the researcher used another statistics variables which was not available in FIBA website, the researcher use these statistics using Microsoft Office Excel 2013 to calculate the following variables:

1. The Effective Field Goal Percentage (EFG\%) is a statistic used in basketball to take into consideration the additional difficulty of three-point shots and the extra points awarded for making a three-pointer, it calculates as (2pt FGM $+1.5 \times 3 \mathrm{pt}$ FGM) / FGA .

2. Offensive Rebounds Efficiency Percentage (EOR\%) , it calculates as [Off. reb. I (missed 2 pt shots + missed 3 pt shots + missed free throws followed by rebounds)] x 100

3. Defensive Rebounds Efficiency Percentage $($ EDR\%), it calculates as [Def. reb. / (missed $2 \mathrm{pt}$ shots + missed 3 pt shots + missed free throws followed by rebounds)] x 100

4. Ball Possessions (BP), it calculates as (Attempted field goals - offensive rebounds + turnovers $-0.4 \times$ Attempted free throws).

5. Efficiency (EEF) is rating teams according to their statistics, it calculates as [ (Points + Rebounds + Assists + Steals + Blocks] - [ (Field Goals Att. Field Goals Made) + (Free Throws Att. - Free Throws Made) + Turnovers) ]

(Gómez M , 2013; Gabor C, 2012; Miguel Á, 2008; Donald H, 2007; Oliver D, 2004)

- The researcher used SPSS Program to discriminate between winning and losing basketball teams U-17 in the championship

1- One sample $t$ test

2- Classification discrimate

3- wilks' lambada

\section{Discussion:}

Table (3)

clears the Mean, Standard Deviation, Wilks' Lambda, F value and Significance Statistical Variables between winning and losing teams

\begin{tabular}{|c|c|c|c|c|c|c|c|c|}
\hline \multirow{2}{*}{ No } & \multirow{2}{*}{$\begin{array}{l}\text { Statistical } \\
\text { Significance }\end{array}$} & \multicolumn{2}{|c|}{ Win } & \multicolumn{2}{|c|}{ Lost } & \multirow{2}{*}{$\begin{array}{c}\text { Wilks' } \\
\text { Lambda } \\
0.01\end{array}$} & \multirow{2}{*}{$\mathrm{F}$} & \multirow{2}{*}{ Sig. } \\
\hline & & Mean & Std. & Mean & Std. & & & \\
\hline 1 & height of players & 198.00 & 0.82 & 192.00 & 3.37 & 0.20 & 12.00 & 0.01 \\
\hline 2 & Field-Goal Made (FGM) & 30.88 & 6.34 & 27.79 & 2.17 & 0.70 & 0.85 & 0.39 \\
\hline 3 & Field-Goal Attempted (FGA) & 70.69 & 5.61 & 69.22 & 4.80 & 0.36 & 0.16 & 0.70 \\
\hline 4 & Field-Goal Percentage (FG\%) & 43.35 & 5.16 & 40.25 & 3.54 & 0.23 & 0.98 & 0.36 \\
\hline 5 & The effective field goal percentage (EFG\%) & 48.07 & 4.40 & 44.82 & 2.18 & 0.50 & 1.76 & 0.23 \\
\hline 6 & 2 Points Made (2PTSM) & 24.32 & 7.40 & 21.25 & 4.18 & 0.92 & 0.52 & 0.50 \\
\hline 7 & 2 Points Attempted (2PTSA) & 48.29 & 11.47 & 47.65 & 5.73 & 0.06 & 0.01 & 0.92 \\
\hline 8 & 1. 2 Points Percentage (2PTS\%) & 49.85 & 2.92 & 44.28 & 3.90 & 0.97 & 5.23 & 0.06 \\
\hline 9 & 1. 3 Points Made (3PTSM) & 6.57 & 1.64 & 6.50 & 3.07 & 0.88 & 0.00 & 0.97 \\
\hline 10 & 1. 3 Points Attempted (3PTSA) & 22.41 & 6.04 & 21.57 & 9.13 & 0.95 & 0.02 & 0.88 \\
\hline
\end{tabular}




\begin{tabular}{|c|c|c|c|c|c|c|c|c|}
\hline \multirow{2}{*}{ No } & \multirow{2}{*}{$\begin{array}{l}\text { Statistical } \\
\text { Significance } \\
\end{array}$} & \multicolumn{2}{|c|}{ Win } & \multicolumn{2}{|c|}{ Lost } & \multirow{2}{*}{$\begin{array}{l}\text { Wilks' } \\
\text { Lambda } \\
0.01\end{array}$} & \multirow{2}{*}{$\mathrm{F}$} & \multirow{2}{*}{ Sig. } \\
\hline & & Mean & Std. & Mean & Std. & & & \\
\hline 11 & 1. 3 Points Percentage (3PTS $\%$ ) & 29.85 & 5.01 & 29.63 & 3.88 & 0.10 & 0.01 & 0.95 \\
\hline 12 & 1. Free-Throws Made (FTM) & 14.47 & 3.32 & 10.18 & 2.87 & 0.09 & 3.83 & 0.10 \\
\hline 13 & 1. Free-Throws Attempted (FTA) & 21.32 & 3.43 & 15.68 & 4.50 & 0.70 & 3.97 & 0.09 \\
\hline 14 & 1. Free-Throws Percentage (FT\%) & 67.60 & 7.17 & 65.33 & 8.67 & 0.27 & 0.16 & 0.70 \\
\hline 15 & Offensive Rebounds (OR) & 16.47 & 2.99 & 14.32 & 1.93 & 0.25 & 1.46 & 0.27 \\
\hline 16 & Offensive Rebounds Efficiency Percentage (EOR\%) & 35.25 & 5.80 & 30.61 & 4.53 & 0.37 & 1.59 & 0.25 \\
\hline 17 & 1. Defensive Rebounds (DR) & 29.66 & 4.81 & 26.00 & 5.93 & 0.43 & 0.92 & 0.37 \\
\hline 18 & Defensive Rebounds Efficiency Percentage (EDR\%) & 63.54 & 10.07 & 55.97 & 14.93 & 0.31 & 0.71 & 0.43 \\
\hline 19 & 1. Total Rebounds (REB) & 46.13 & 7.18 & 40.32 & 7.55 & 0.17 & 1.24 & 0.31 \\
\hline 20 & 1. Assists (AST) & 16.19 & 2.65 & 13.43 & 2.29 & 0.60 & 2.49 & 0.17 \\
\hline 21 & 1. Personal Fouls (PF) & 18.60 & 2.22 & 19.61 & 2.90 & 0.04 & 0.31 & 0.60 \\
\hline 22 & 1. Turnovers (TO) & 15.91 & 2.11 & 19.79 & 1.94 & 0.42 & 7.34 & 0.04 \\
\hline 23 & 1. Steals $(\mathrm{ST})$ & 10.75 & 2.04 & 9.79 & 0.90 & 0.32 & 0.75 & 0.42 \\
\hline 24 & 1. Block Shots (BS) & 3.72 & 0.87 & 4.79 & 1.77 & 0.62 & 1.16 & 0.32 \\
\hline 25 & Ball possessions (BP) & 61.60 & 3.22 & 68.41 & 3.80 & 0.03 & 7.46 & 0.62 \\
\hline 26 & Efficiency (EEF) & 90.44 & 23.04 & 67.36 & 12.82 & 0.13 & 3.07 & 0.03 \\
\hline
\end{tabular}

Table (4)

clears the Classification Results for each of the winning and losing team (The research sample)

\begin{tabular}{|c|c|c|c|c|c|}
\hline & \multirow{2}{*}{\multicolumn{2}{|c|}{ Code }} & \multicolumn{2}{|c|}{ Predicted Group Membership } & \multirow{2}{*}{ Total } \\
\hline & & & Win & Lost & \\
\hline \multirow{4}{*}{ Original } & \multirow{2}{*}{ Count } & Win & 4.00 & 0.00 & 4.00 \\
\hline & & Lost & 0.00 & 4.00 & 4.00 \\
\hline & \multirow{2}{*}{$\%$} & Win & 100.00 & 0.00 & 100.00 \\
\hline & & Lost & 0.00 & 100.00 & 100.00 \\
\hline
\end{tabular}

Table (5)

clears the entered Statistical Variables, Wilks' Lambda and Exact $\mathbf{F}$ to compare between winning and losing teams

\begin{tabular}{|c|c|c|c|}
\hline Step & Entered & Wilks' Lambda & Exact F \\
\hline 1 & Height of players & 0.33 & 12.00 \\
\hline 2 & Defensive Rebounds Efficiency Percentage (EDR\%) & 0.18 & 11.27 \\
\hline 3 & Free-Throws Made (FTM) & 0.04 & 36.61 \\
\hline
\end{tabular}

- Eigenvalue

$12.381^{\mathrm{a}}$

- Variance

$100 \%$

- Canonical Correlation 0.96
- Wilks' Lambda

0.07

- Chi-square 
Table (6)

clears Standardized Canonical Discriminant Function Coefficients to compare between winning and losing teams

\begin{tabular}{|c|c|}
\hline Variables & Function 1 \\
\hline Height of players & -1.41 \\
\hline Field-Goal Made (FGM) & -19.47 \\
\hline Field-Goal Attempted (FGA) & 6.27 \\
\hline The effective field goal percentage (EFG\%) & 10.35 \\
\hline 2 Points Attempted (2PTSA) & 7.94 \\
\hline
\end{tabular}

Table (3) clears Mean, Standard deviation, Wilks' Lambda and $\mathrm{F}$ value for winning and losing teams which appear primarily and discriminate between winning and losing teams in some variables, then, Wilks' Lambda is a test which uses to analyses the differences in one direction for two levels. (Rencher, A., Christensen W., 2012)

It clears from table (4) the classification results shows the success percentage of function $100 \%$, which indicate that the variables covers all the aspects of winning and losing.

It clears from table $(5,6)$ that the discriminate statistic variables in winning and losing for Junior teams under 17 as follow:

1. Height of players

2. Defensive Rebounds Efficiency Percentage (EDR\%)

3. Free-Throws Made (FTM)

4. Field-Goal Made (FGM)

5. Field-Goal Attempted (FGA)

6. The effective field goal percentage (EFG\%)

7. 2 Points Attempted (2PTSA)

The Height of players discriminated for winning players with average $198 \mathrm{~cm}$, while the height of players for losing teams was $192 \mathrm{~cm}$, the researcher refers that to the distinguished selecting of players in mini-basket which contributed to provide a wide range of selecting the suitable height for the game from junior to the first team, therefore, there is a relation between height of players and offensive and defensive efficiency in basketball, especially in young ages where there are differences in players' heights ( Oliver D 2004 ).

The researcher refers the discriminatory in Defensive Rebounds Efficiency Percentage to the height of players and miss shot, which enter the function of EDR\%, the rebound depends basically on player's height, leg's exclusive power, skills performance and good timing of rebound. (Sampaio and Janeira, 2003) ensure that winning teams present taller and stronger players that secure more defensive rebounds, thus allowing making more fast-breaks. The researcher finds that the discriminatory of defense rebound reduce the ability of the opponent in offense, and couldn't follow the offense. It shows the relationship between numbers of rebounds and winning, which is to say a higher number of rebounds, means better opportunity to win the match (Sampaio, Ibáñez, \& Feu, 2004).

The winning teams discriminate in Free-Throw Made with average of 14.47 point in the game compare to 10.18 point for the losing teams; the researcher refers that discriminate to the training of free throw in stimulating situations of the game physically, legally and psychologically. (Lee R, 2012) ( Julio G, 2007) mentioned that training on free throw performance while the player under pressure similar to the actual game with focusing on the legal 5 seconds for shooting free throw on the basket. ( Julio G, 2007) ensure that there is a relationship between winning a game and free throw made which is one of the most important variable of winning, especially in the last five minutes of the game.

Also, the winning team discriminated in variables as FieldGoal Made, Field-Goal Attempted, the researcher refers the variables in FGA \& FGM to the continuous shooting attempts for winning team compare to losing team in result of good tactic and skills performance. The average of FGA for winning team was 70.69 try, while 69.22 for losing team, and the average of FGM for winning team was 30.88, while it was 27.79 for losing team. When FGA \& FGM are high, that will increase the possibility of winning (Oliver D, 2004).

The winning teams discriminated in the effective field goal percentage, which was $48.07 \%$ for winning teams and $44.82 \%$ for losing teams, the researcher refers that to the discriminatory of winning teams in variables 2 ptM \& FGA, these variables enter the EFG \% formula in addition to 3 FGM.

Effective Field Goal Percentage is a measurement of how successful your team (Oliver D 2004). The study of (Haris P et al, 2009) showed the EFG \% variable that makes the most significant difference between victorious and defeated teams.

The winning teams discriminated in 2 Point Attempted with average of 48.29 attempts per game compare to 47.65 attempts for losing teams. Most of these studies conclude that two point shots is the chief determinants of winning (Miguel Á et al., 2008; Ibáñez et al., 2003) . Winning and losing teams were discriminated by successful 2 point fieldgoals and defensive rebounds. This last game-related 
statistic is the basis for team play because it opens up more opportunities for primary and secondary fast-breaks and assists. Additionally, it reduces the chances for the opponents' efficiency by not allowing them an extra ball possession, decreasing their shooting attempts, their drawing fouls play and their effectiveness in transition defense (Trninić et al., 2002).
According to the previous results, it clears the answer for the first question which is:

- What are the most effective statistics for discriminating winning and losing teams in World Championship for Men U-17?

Table (7)

clears Mean Difference, $T$ value and significant between winning teams $(n=4)$ and Egypt team

\begin{tabular}{|c|c|c|c|c|c|c|c|}
\hline \multirow{2}{*}{ No } & \multirow{2}{*}{$\frac{\text { Statistical Significar }}{\text { variables }}$} & \multicolumn{2}{|c|}{ Win } & \multirow{2}{*}{ EGYPT } & \multirow{2}{*}{$\begin{array}{c}\text { Mean } \\
\text { Difference }\end{array}$} & \multirow{2}{*}{$\begin{array}{c}\mathrm{T} \\
\text { value }\end{array}$} & \multirow{2}{*}{ significant } \\
\hline & & Mean & Std. & & & & \\
\hline 1 & height of players & 198 & 0.82 & 191 & 7 & 17.15 & $0.00^{*}$ \\
\hline 2 & Field-Goal Made (FGM) & 30.88 & 6.34 & 28.14 & 2.74 & 0.86 & 0.45 \\
\hline 3 & Field-Goal Attempted (FGA) & 70.69 & 5.61 & 65.29 & 5.40 & 3.93 & $0.04 *$ \\
\hline 4 & Field-Goal Percentage (FG\%) & 43.35 & 5.16 & 43.10 & 0.25 & 0.10 & 0.93 \\
\hline 5 & The effective field goal percentage (EFG\%) & 48.07 & 4.40 & 44.75 & 3.32 & 1.51 & 0.23 \\
\hline 6 & 2 Points Made (2PTSM) & 24.32 & 7.40 & 25.57 & -1.26 & -0.34 & 0.76 \\
\hline 7 & 2 Points Attempted (2PTSA) & 48.29 & 11.47 & 54.71 & -6.43 & -1.12 & 0.34 \\
\hline 8 & 2. 2 Points Percentage (2PTS\%) & 49.85 & 2.92 & 46.70 & 3.15 & 2.16 & 0.12 \\
\hline 9 & 2. 3 Points Made (3PTSM) & 6.57 & 1.64 & 2.43 & 4.14 & 5.06 & $0.01 *$ \\
\hline 10 & 2. 3 Points Attempted (3PTSA) & 22.41 & 6.04 & 10.57 & 11.84 & 3.92 & $0.03^{*}$ \\
\hline 11 & 2. 3 Points Percentage (3PTS $\%$ ) & 29.85 & 5.01 & 24.30 & 5.55 & 2.22 & 0.11 \\
\hline 12 & 2. Free-Throws Made (FTM) & 14.47 & 3.32 & 11.47 & 2.90 & 1.75 & 0.18 \\
\hline 13 & 2. Free-Throws Attempted (FTA) & 21.32 & 3.43 & 19.71 & 1.61 & 0.94 & 0.42 \\
\hline 14 & 2. Free-Throws Percentage (FT\%) & 67.60 & 7.17 & 58.70 & 8.90 & 2.48 & 0.09 \\
\hline 15 & Offensive Rebounds (OR) & 16.47 & 2.99 & 13.14 & 3.33 & 2.23 & 0.11 \\
\hline 16 & Offensive Rebounds Efficiency Percentage (EOR\%) & 35.25 & 5.80 & 28.93 & 6.32 & 2.18 & 0.12 \\
\hline 17 & 2. Defensive Rebounds (DR) & 29.66 & 4.81 & 25.00 & 4.66 & 1.94 & 0.15 \\
\hline 18 & Defensive Rebounds Efficiency Percentage (EDR\%) & 63.54 & 10.07 & 55.03 & 8.51 & 1.69 & 0.19 \\
\hline 19 & 2. Total Rebounds (REB) & 46.13 & 7.18 & 38.14 & 7.99 & 2.22 & 0.11 \\
\hline 20 & 2. Assists (AST) & 16.19 & 2.65 & 10.43 & 5.76 & 4.35 & $0.02 *$ \\
\hline 21 & 2. Personal Fouls (PF) & 18.60 & 2.22 & 16.14 & 2.46 & 2.21 & 0.11 \\
\hline 22 & 2. Turnovers (TO) & 15.91 & 2.11 & 22.29 & -6.38 & -6.05 & $0.01 *$ \\
\hline 23 & 2. Steals (ST) & 10.75 & 2.04 & 9.29 & 1.46 & 1.43 & 0.25 \\
\hline 24 & 2. Block Shots & 3.72 & 0.87 & 7.43 & -3.71 & -8.50 & $0.00 *$ \\
\hline 25 & Ball possessions (BP) & 61.60 & 3.22 & 66.54 & -4.94 & -3.07 & $0.05^{*}$ \\
\hline 26 & Efficiency (EEF) & 90.44 & 23.04 & 65.57 & 24.87 & 2.16 & 0.12 \\
\hline
\end{tabular}

$P$ value $>0.05 \neq$ no significant

\section{$P$ value $\leq 0.05=$ significant $*$}

Table (7) clears the differences between winning teams and Egyptian team in the statistical variables under research, where there are significant differences in $\mathrm{P}$ value for the winning teams in the following variable: 
1. height of players

2. Field-Goal Attempted

3. 3 Points Made

4. 3 Points Attempted

5. Assists

Also it appears in Table (7) significant differences in $\mathrm{P}$ value for the Egyptian team in the following variables:

\section{Turnovers}

2. Block Shots

3. Ball possessions

Table (7) shows significant differences for winning teams in height of players, the average of players' height in winning teams was $198 \mathrm{~cm}$, while it was $191 \mathrm{~cm}$ for the Egyptian team. This result clears the necessary early selecting taller players and monitors the training process leads to reach high level of championship (Mohamed S \& Mohamed M, 1999).

Table (7) shows significant differences for winning teams in Field-Goal Attempted, the average of FGA in winning teams was 70.69 , while it was 65.29 for the Egyptian team. When FGA \& FGM are high, that will increase the possibility of winning (Oliver D, 2004).

It clears from table (7) the significant differences for the winning teams in 3 Points Made and 3 Points Attempted, the average of $3 \mathrm{ptA}$ for winning was 22.41 shot attempts, while it was 10.57 attempts for the Egyptian team. The average of 3 ptM for winning was 6.57 shots while it was 2.43 shot for Egyptian team. This results ensure the important of training on 3 point shot and selecting players distinguished in three point shooting, especially when team participate in international championships. While there are no significant differences between the Egyptian team and winning teams in offensive rebound, and there are significant differences for Egyptian team in two points, then if the Egyptian team discriminates with three points shot that will give the team the opportunity to win the game. Where (Lee R, 2012) ensure that Three points is one of the most interesting offensive trends that has seemed to have a significant effect on playing and coaching.

Table (7) shows significant differences in Assists with average of 16.19 for winning teams, where it was 10.43 Assist pass for the Egyptian team. An assist is a pass that leads directly to a team-mate scoring, only if the player scoring the wwgoal responds by demonstrating immediate reaction towards the basket (Official Basketball Statisticians' Manual, 2012). The study of ( Sergio J et al.,2009, Miguel Á et al, 2008, Sampaio J et al, 2004 ) ensure that Assists Pass is one of the indicator for winning and losing teams in Basketball.

Also the results showed in table (7) significant differences for Egyptian team in Turnover, where it was 15.91for winning and 22.29 turnover for Egyptian team. Which indicate mistakes in offense skills in Egyptian team and it leads to cut the ball and give the opportunity to the opponent to transition from defense to fast break. A turnover is a mistake by an offensive player or team that results in the defensive team gaining possession of the ball without the offensive team having attempted a field goal or free throw, except when a period expires without a field goal attempt. (Official Basketball Statisticians’ Manual, 2012)

Table (7) also clears that there are significant differences in Block Shot for the Egyptian team, where the average was 3.72 for winning team and 7.43 for Egyptian team, which shows the discriminatory in this variable for the Egyptian team.

Finally, it appears in table (7) significant differences for Egyptian team in Ball Possessions, which was 61.60 for winning team and 66.54 for Egyptian team, the researcher conclude that the Ball Possessions is not an important variable that effect in winning game, where the ball possessions strategy for long period during offense reduce the Field Goal Attempts and therefore lead to losing team. Research also attempted to relate the championships final classification with game ball possessions, offensive and defensive ratings. After analyzing five world championships (under-18, senior, men's, and women's), (Ibáñez et al, 2003) concluded that the best ranked teams had higher offensive coefficients and fewer ball possessions.

According to the previous results, it clears the answer for the second question which is:

- What are the most effective statistics for losing Egyptian team in FIBA U-17 World Championship for Men 2012?

\section{Conclusions:}

Within the results reached and data analysed, the researcher obtained the following conclusion:

1- The discriminatory power of game-related statistics allows Coaches to understand that winning team in game depends on winning variables as it appears in the research. These variables help the coaches to prepare practices according to this specificity and, to be ready to control these variables in competition for players under 17.

2- Coaches should be aware that dominating the following variables will increase the probability to win the games for Junior teams under 17:

- Height of players

- Defensive Rebounds Efficiency Percentage (EDR $\%)$

- Free-Throws Made (FTM)

- Field-Goal Made (FGM) 
- Field-Goal Attempted (FGA)

- The effective field goal percentage (EFG \%)

- 2 Points Attempted (2PTSA)

The most effective statistics variables for losing Egyptian team in FIBA U-17 World Championship for Men 2012 as follow:

1. height of players

2. Field-Goal Attempted (FGA)

3. 3 Points Made (3PTSM)

4. 3 Points Attempted (3PTSA)

5. Assists (AST)

6. Turnovers (TO)

7. Ball possessions (BP)

8. The best ranked teams had higher offensive coefficients and fewer ball possessions.

9. The values of the present paper can serve as a guide or reference to design and control training and exercises in order to participate in competitions and ensure winning games.

\section{Recommendations:}

1- Using the winning variables outcomes from the current study to select players for the Egyptian National Basketball Team to participate in World Championship U 17.

2- Focus on winning variables during the training process for the players $U 17$, especially during their preparation to participate in the World Championship.

3- Study the winning and losing variables for other Basketball Egyptian teams in different tournaments and championship.

\section{References:}

1- Christoforidis, C., Papadimitrou, K., Taxildaris, K., Aggelousis, N. and Gourgoulis, V. (2000) Evaluation of free shot contribution in winning a basketball game during European Championships. Exercise and Society Journal of Sports Science 24, 68-72.

2- Clive Gifford,( 2009 ) Basketball, Marshall Cavendish, Sep 1, p 6

3- Csataljay G, O’Donoghue P, Hughes MD, Dancs H.( 2009) Performance indicators that distinguish winning and losing teams in basketball. International Journal of Performance Analysis in Sport.; 9(1):6066.

4- Donald H. Brown,( 2007) A Basketball Handbook, AuthorHouse, p 59.

5- Gabor Csataljay, Nic James, Mike Hughes, Henriette Dancs,(2012) Performance differences between winning and losing basketball teams during close, balanced and unbalanced quarters, Journal of Human Sport \& Exercise, volume 7, Issue 2, 3563364.

6- Gómez MA, Lorenzo A, Ibañez SJ, Sampaio J.,( 2013) Ball possession effectiveness in men's and women's elite basketball according to situational variables in different game periods, $\mathbf{J}$ Sports Sci.;31(14):1578-87. doi: 10.1080/02640414.2013.792942.

7- Gómez, M.A., Lorenzo, A., Sampaio, J. and Ibáñez, S.J. (2006) Differences in game-related statistics between winning and losing teams in women's basketball. Journal of Human Movement Studies 51, 357-369.

8- Haris Pojskić, Vlatko Šeparović and Edin Užičanin, (2009) Differences between successful and unsuccessful Basketball Teams on the final Olympic Tournament, Acta Kinesiologica p 110-114.

9- Ibáñez, S.J., Sampaio, J., Sáenz-López, P., \& Giménez, F.J.(2003). Game statistics discriminating the final outcome of junior world basketball championship matches (Portugal, 1999). Journal of Human Movement Studies, 45, 1-19.

10-Julio Garry Guerrero, (2007) Measures Affecting Free-throw Shooting in Big 12 Conference Men's Basketball Games, ProQuest,p 48.

11-Lee Rose,(2012) Winning Basketball Fundamentals, Human Kinetics, p 100-120.

12-Miguel Ángel Gómez, Alberto Lorenzo, Jaime Sampaio, Sergio José Ibáñez and Enrique Ortega. (2008) Game Related Statistics that Discriminated Winning and Losing Teams from the Spanish Men's Professional Basketball Teams, Coll. Antropol. 32: $451-456$

13-Mohamed Sobhy., Mohamed abd Eldaem, (2001) Modern in Basketball, Arabic Thought publishing. 
14-Official Basketball Statisticians' Manual 2012, www.fiba.com.

15-Oliver Dean (2004), Basketball on paper. Rules and tools for performance analysis. Washinton, D.C.: Brassey's.

16-Rencher, A. C., Christensen W. F. (2012), Methods of Multivariate Analysis. 3rd ed. Hoboken, NJ: Wiley.

17-Sampaio J, Godoy SI, FEU S.( 2004) Discriminative power of basketball game-related statistics by level of competition and sex. Perceptual and Motor Skills; 99:1231-8.

18-Sampaio J, Janeira M.(2003) Statistical analyses of basketball team performance: understanding teams' wins and losses according to a different index of ball possessions. International Journal of Performance Analysis in Sport; 3(1):40-49.

19-Sergio J. Ibáñez, Javier García, Sebastian Feu, Alberto Lorenzo and Jaime Sampaio, (2009) Effects of consecutive basketball games on the game-related statistics that discriminate winner and losing teams, Journal of Sports Science and Medicine 8, 458 - 462

20-Tavares F, Gomes N.( 2003) The offensive process in basketball - a study in high performance junior teams. International, Journal of Performance Analysis in Sport. 34- 39.

21-Trninc S, Dizdar D, Luksic E.( 2002) Differences between winning and defeated top quality basketball teams in final of European club championship. Collegium Antropologicum; 26(2):521-31.

22-www.breakthroughbasketball.com/stats/efg_calc.ht $\underline{\text { ml\#ixzz2mvcMrZH5 }}$

23-www.fiba.com

24-www.nba.com/statistics/efficiency.html 
